\title{
Destruction of Azo-Reactive Dyes by 0zonation and the Synergetic Effect of a Radio-Frequency Alternating Electric Field Inductance Device
}

\author{
Dimitrios Georgiou*, Manolis Kalis, George Patermarakis and Alexandros A Vassiliadis \\ Department of Textile Engineering, Dyeing and Finishing Laboratory, Piraeus University of Applied Sciences (Technological Education Institute of \\ Piraeus), Greece
}

Submission: September 25, 2017; Published: November 14, 2017

*Corresponding author: Dimitrios Georgiou, Dyeing and Finishing Laboratory, Department of Textile Engineering, Piraeus University of Applied Sciences, 250 Thivon Street, 12244 Athens, Greece, Tel. No: +30 210 5381171; E-mail: dgeorgiou66@yahoo.com

\begin{abstract}
Discharge of textile wastewater into water-bodies causes serious environmental and health problems. Wastewater color remains due to the non-biodegradable nature of the dyes. However, treatment with ozone can lead to the destruction of the dye molecule, decolorizing thus the textile effluent. In this paper, treatment with ozone in a bubble column reactor resulted in rapid destruction of azo-reactive dyes, utilized primarily for dyeing cellulose fibers. Moreover, ozonation kinetics can be described as a mass-transfer-control process. Combining ozonation with a novel radio-frequency alternating electric field inductance device led to faster destruction of the azo-reactive dyes due to synergetic effects.

Keywords: Azo-reactive dyes; Alternating electric field; Bubble column reactor; Ozonation; Radio-frequency; Textile wastewater
\end{abstract}

\section{Introduction}

Ozone, the triatomic, allotropic form of oxygen is a very powerful oxidant with many commercial and industrial applications. Its name is the derivative of the Greek verb "OZQ", meaning "I smell bad", due to its characteristic unpleasant odor. Ozone is used commonly in potable and non-potable water treatment, as well as in industrial wastewater management. The considerable oxidizing power of ozone and its molecular oxygen by-products make it a first choice for oxidation or disinfection over the many various chemical alternatives. It is indeed one of the most active, readily available oxidizing agents that can be generated on-site. Furthermore, ozone rapidly decomposes to oxygen leaving no traces, while its reactions do not produce, in general, toxic substances (e.g., halogenated compounds). It reacts, directly or indirectly, with complex organic and inorganic compounds breaking them into simpler and smaller molecules. The oxidizing action of ozone in aqueous solutions is rather complex since ozone acts by several mechanisms, including the presence of other highly strong oxidizing agents, like atomic oxygen $(|\mathrm{O}|)$, perhydroxyl $\left(\mathrm{HO}_{2} \bullet\right)$, or hydroxyl $(\mathrm{OH} \bullet)$ free radicals. In practice, both direct and indirect oxidation reactions occur. However, one kind of reaction usually dominates, depending on various factors, such as temperature, $\mathrm{pH}$, and chemical composition of the aqueous solution [1-3].
Direct oxidation of organic compounds takes place via a quite selective reaction mechanism, during which ozone reacts quickly with compounds that contain double bonds, activated aromatic groups or amines. Moreover, the ozone molecule can act in three different ways; (1) as a 1,3-dipole; undergoing a 1-3 dipolar cyclo-addition with unsaturated organic compounds; (2) as an electrophilic agent; in molecular solutions that have a high electronic density (e.g., aromatic compounds), and (3) as a nucleophilic agent; in reactions with carbon compounds that contain electron-withdrawing groups (e.g., $-\mathrm{COOH}$ and $-\mathrm{NO}_{2}$ ) [47].

On the other hand, indirect reactions in an ozone oxidation process can be very complex. As a matter of fact, an indirect reaction takes place according to the following steps: (1) Initiation; leading to the formation of free radicals (e.g., $\mathrm{O}_{2} \bullet$, $\mathrm{HO}_{2} \bullet, \mathrm{OH} \bullet$ ), (2) Radical chain-reaction; a chain-reaction develops which is maintained by the so-called promoters (e.g., primary and secondary alcohols). The reaction speed of hydroxyl radicals $(\mathrm{OH} \bullet)$ is thousands of times higher than that of ozone. However, this does not mean that hydroxyl radical oxidation always takes place more rapidly than ozone oxidation. Hydroxyl radicals are consumed by radical inhibitors (e.g., $\mathrm{HCO}_{3}-/ \mathrm{CO}_{3}{ }^{2-}, \mathrm{PO}_{4}{ }^{3-}$, humic acids) in water much faster than ozone, and (3) Termination 
the final reactions take place where harmful substances are decomposed to less harmful substances, or even completely mineralized [4-7].

Among ozone's numerous applications, decoloration of textile wastewater has gained an increasing interest the recent years. Discharge of dye-containing effluents into water bodies causes serious environmental and health problems. The effluents are toxic and carcinogenic with a complex structure mainly based on aromatic amines that also generate toxic by-products of their partial degradation. Wastewater from textile dyeing processes is very hard to treat by conventional activated sludge systems. Wastewater color remains due to the non-biodegradable nature of the dyes. Physico-chemical methods such as, coagulation/ flocculation, clay, perlite and activated carbon adsorption, as well as reverse osmosis techniques, have been developed in order to remove the color. However, the latter methods can only transfer the contaminants (dyes and dye by-products) from one phase to the other, leaving the problem essentially unsolved [813]. Therefore, attention had to be focused on techniques that lead to the destruction of the dye molecules.

Advanced Oxidation Processes (AOPs), such as, treatment with ozone (O3), Ultra Violet and Hydrogen Peroxide ( $\mathrm{UV} / \mathrm{H}_{2} \mathrm{O}_{2}, \mathrm{UV} / \mathrm{O}_{3}$ ) $\mathrm{H}_{2} \mathrm{O}_{2}$ ), can lead to destruction of the dye-molecule chromophore

\section{Experimental}

\section{Reagents}

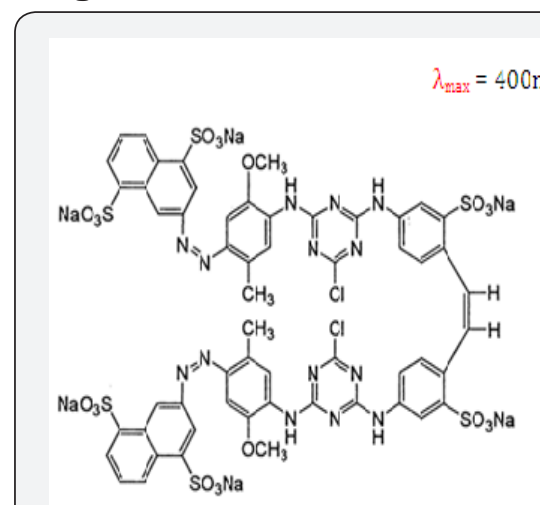

(a)

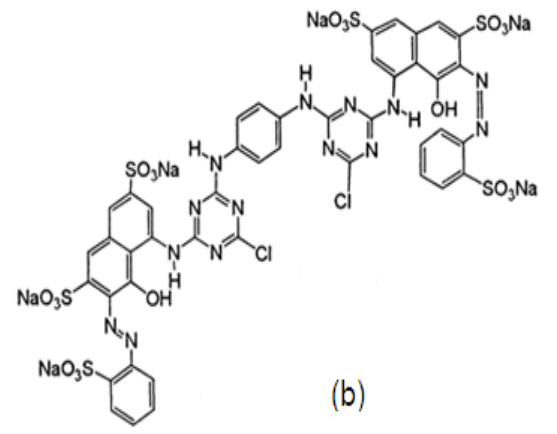

(b) group, decolorizing thus the textile effluent. More specifically, the azo double bond $(-N=N-)$ in azo textile dyes breaks initially leading to the formation of intermediate colorless products (e.g., nitrosamines). The latter products can be further degraded to simpler products till complete mineralization [14-17]. Moreover, the synergetic effects of ozonation, combined with other treatment techniques, like Ultra-Sound, $U V$ and $\mathrm{H}_{2} \mathrm{O}_{2}\left(U S / \mathrm{O}_{3^{\prime}}\right.$ US $/$ $\mathrm{O}_{3} / \mathrm{UV}, \mathrm{US} / \mathrm{O}_{3} / \mathrm{H}_{2} \mathrm{O}_{2}$ ) have also showed promising results [18-20]. Finally, AOPs like several pulsed power treatment techniques, which in situ generate highly strong oxidizing agents (e.g., $\mathrm{OH} \bullet$, $\mathrm{H} \bullet, \mathrm{O} \bullet, \mathrm{H}_{2} \mathrm{O}_{2}, \mathrm{O}_{2}, \mathrm{O}_{3}$ ), have been tested on azo-dye effluents with success the recent years [21-24].

The objective of this paper is, firstly, to demonstrate the ability of ozonation to fully and effectively decolorize aqueous solutions of azo-reactive dyes, and secondly, to investigate the synergetic effect of a Radio-Frequency Alternating Electric Field (RFAEF) inductance device on the ozonation of the above dyes. All the experiments were carried out in a Bubble Column Reactor (BCR). Bubble column reactors are widely used in chemical, petrochemical, biochemical, and metallurgical industries. The absence of moving parts, their low operating and maintenance costs and the excellent mass and heat transfer rates explain the large number of applications developed with this type of reactor $[25,26]$.

\footnotetext{
A) RY84: Evercion Yellow H-E4R (C.I. Reactive Yellow 84)

Molecular Formula: $\mathrm{C}_{56} \mathrm{H}_{38} \mathrm{Cl}_{2} \mathrm{~N}_{14} \mathrm{Na}_{6} \mathrm{O}_{20} \mathrm{~S}_{6}$ (Molecular Weight: 1628.22)

B) RR120: Evercion Red H-E3B (C.I. Reactive Red 120)

Molecular Formula: $\mathrm{C}_{44} \mathrm{H}_{24} \mathrm{Cl}_{2} \mathrm{~N}_{14} \mathrm{O}_{20} \mathrm{~S}_{6} \mathrm{Na}_{6}$ (Molecular Weight: 1469.98)

C) RB198: Evercion Blue H-EGN (C.I. Reactive Blue 198)

Molecular Formula: $\mathrm{C}_{41} \mathrm{H}_{30} \mathrm{Cl}_{4} \mathrm{~N}_{14} \mathrm{Na}_{4} \mathrm{O}_{14} \mathrm{~S}_{4}$ (Molecular Weight: 1304.80)

Figure 1: Molecular and structural formulae of the azo-reactive dyes.
}

Three (3) of the most representative and commonly used azo-reactive dyes, most suitable for dyeing cotton and polyester/ cotton blended fabric, were tested. More specifically, the dyes used were: C.I. Reactive Yellow 84 (RY84), C.I. Reactive Red 120
(RR120) and C.I. Reactive Blue 198 (RB198), manufactured by "Everlight Chemical Industrial Co." (Taiwan); they are highly soluble in water and their characteristics and structural formulae are given in Figure 1 [27]. 


\section{The radio-frequency alternating electric field inductance device}

Our novel electronic device operated at $12 \mathrm{~V}$ and its output induced in water a $6,000 \mathrm{~V}$ alternating electric field of a frequency of $600 \mathrm{kHz}$ (medium frequency radio band), with the aid of an advanced oscillator. Moreover, the magnetic induction was practically zero $\left(\sim 1 \times 10^{-12}\right.$ Gauss $)$ and there was no need for an earth-electrode. Furthermore, the alternating electric field was $100 \%$ of the sinewave type, producing a minimum number of harmonic frequencies (Figure 2).

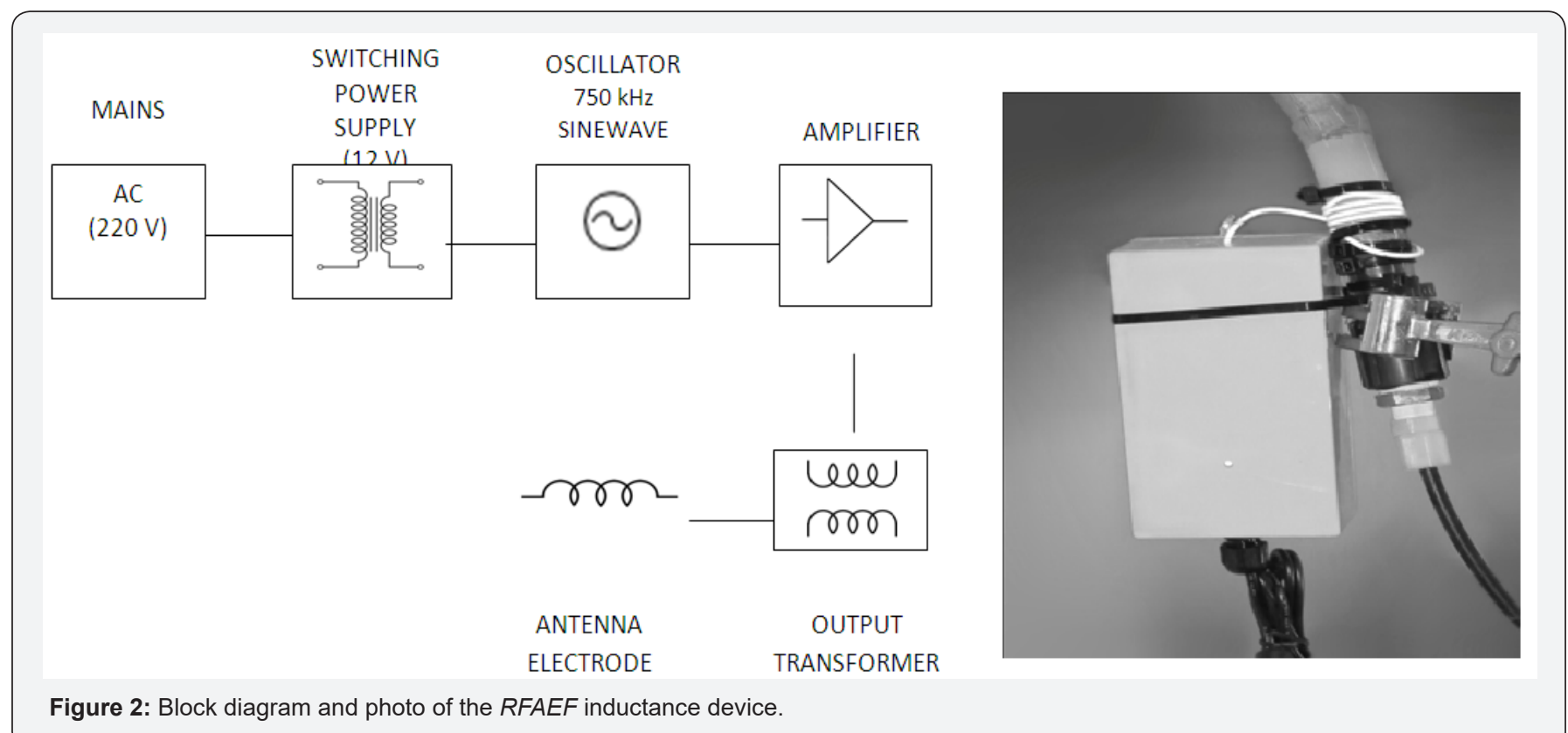

\section{The bubble column reactor}

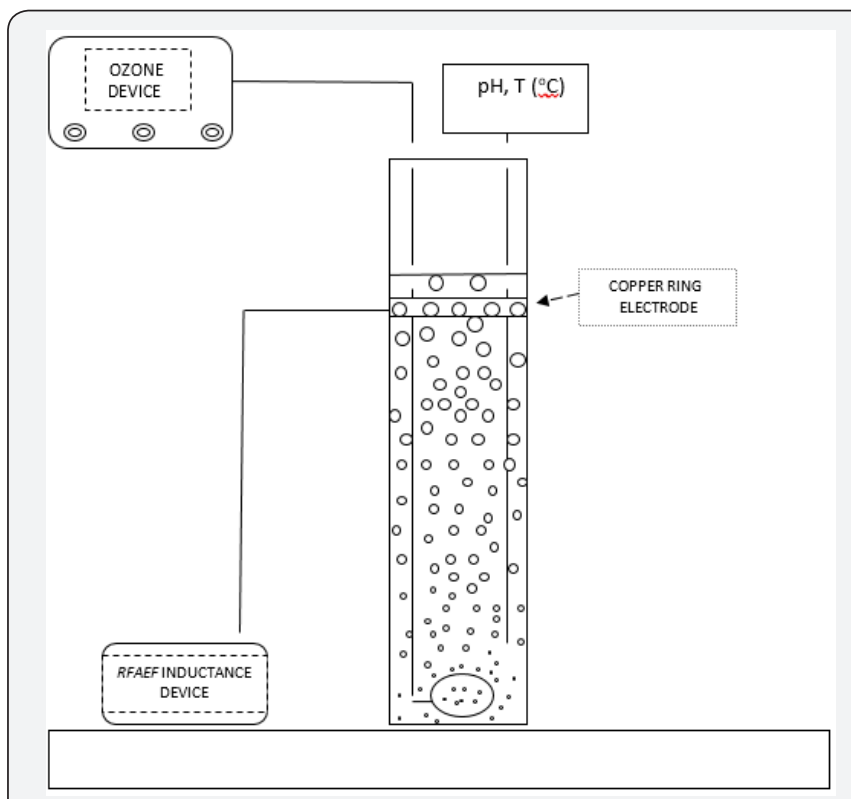

Figure 3: Schematic diagram of the bubble column reactor.

All experiments were carried out in a semi-batch mode bubble column reactor (Diameter: $5 \mathrm{~cm}$, Volume: $250 \mathrm{~mL}$ ). The RFAEF inductance device was connected with the bubble column reactor by means of a copper ring electrode that was attached on the external surface of the reactor; just under the top of the water level (Figure 3). An "Ozone Purifier" (Guanglei,

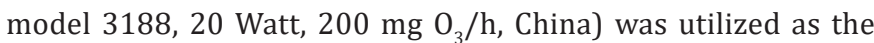
ozone source. All the experiments were carried out at ambient conditions (temperature range: $18-22^{\circ} \mathrm{C}$ ); $\mathrm{pH}$ and temperature were measured by a Hanna, HI $8424 \mathrm{pH}-$ meter. The dye aqueous solutions (50 $\mathrm{mg} / \mathrm{L})$ were prepared immediately before experimentation using deionized water. Samples were withdrawn from the reactor at certain time intervals, filtrated with $0.45 \mu \mathrm{m}$ pore filters and the dye-content was immediately determined utilizing a UV/VIS Hitachi U-1100 spectrophotometer. The wavelength of the maximum absorbance $\left(\lambda_{\max }\right.$, Figure 1$)$ was used for each dye-sample measurement.

\section{Results and Discussion}

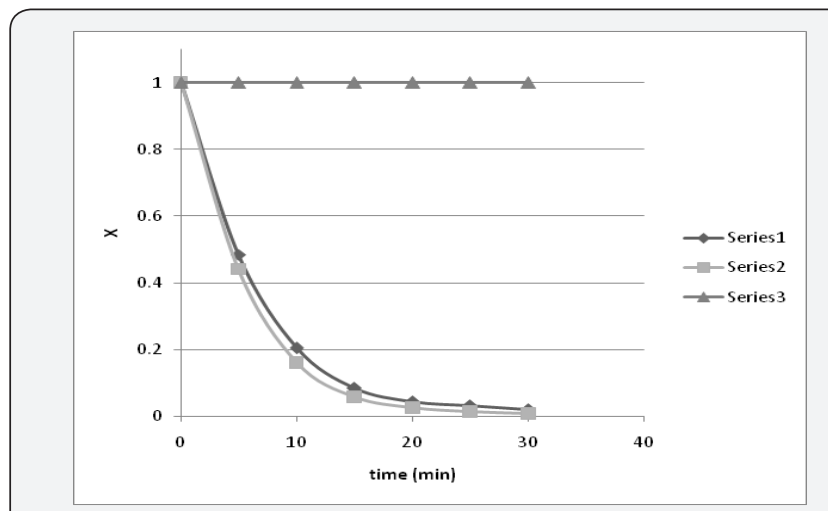

Figure 4: Remaining portion $(X)$ of dye (RY84) in aqueous solution vs. time (Series 1: Ozone, Series 2: Ozone/RFAEF, Series 3: RFAEF). 


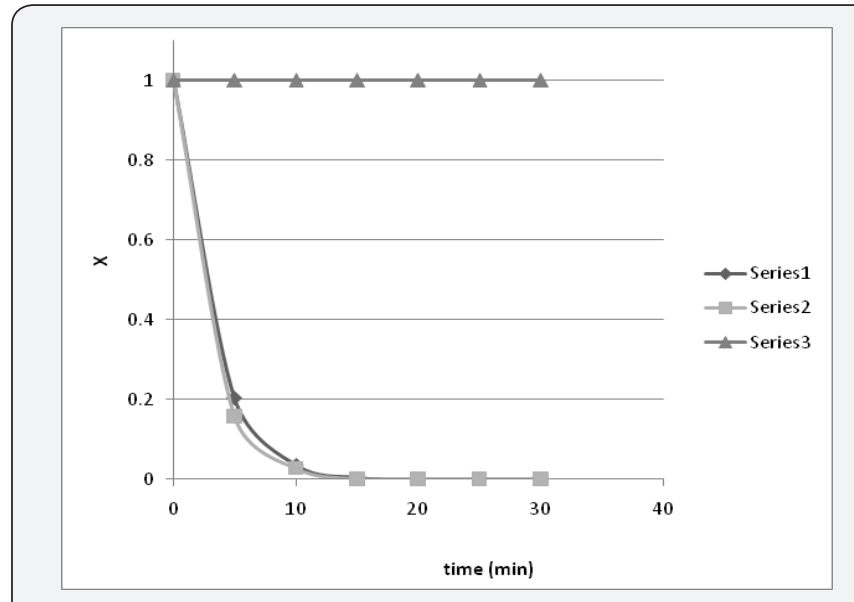

Figure 5: Remaining portion $(\mathrm{X})$ of dye $(R R 120)$ in aqueous solution vs. time (Series 1: Ozone, Series 2: Ozone/RFAEF, Series 3: RFAEF)

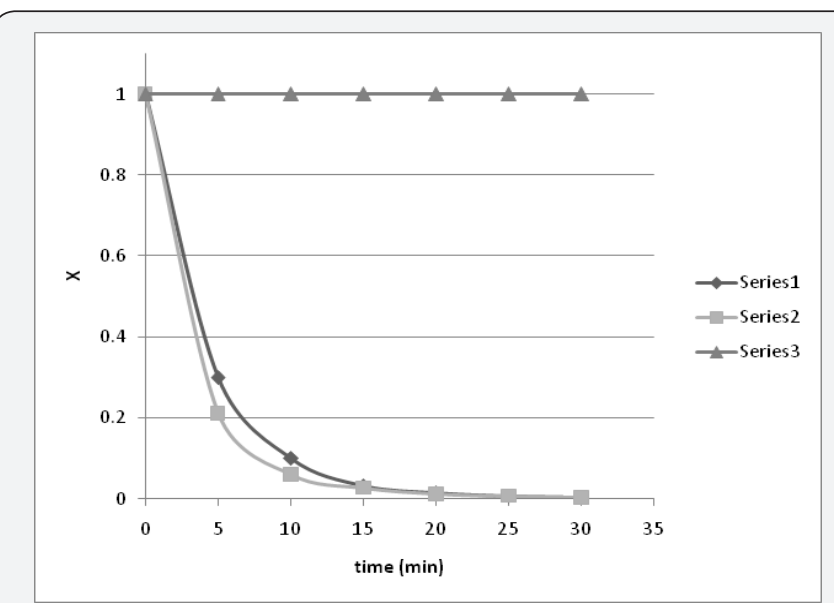

Figure 6: Remaining portion (X) of dye (RB198) in aqueous solution vs. time (Series 1: Ozone, Series 2: Ozone/RFAEF, Series 3: RFAEF)

Three (3) different experiments were performed for each azo-reactive dye aqueous solution. Firstly, the possible effect of the RFAEF inductance device alone on decoloration was investigated. For these experiments, an impeller was introduced in the bubble column reactor, in order to provide adequate agitation. Secondly, ozonation of the dye solutions without the above electronic device was performed. Finally, combination of ozonation with the RFAEF inductance device and the possible synergetic effects were investigated. The decoloration results of all the experiments are presented in Figures 4-6.

Treatment with the RFAEF inductance device alone did not show any observable reduction in the color of the dye-aqueous solutions, at least in the first $30 \mathrm{~min}$ of the experiment, as depicted in Figures 4-6. It's been well-established that strong oxidizing agents (free radicals, ozone) are created in an aqueous solution under an intense pulsed electromagnetic field [23,24]. However, in our case, the concentration of the above oxidizing agents was obviously very low to cause decoloration of the dyeaqueous solutions.

Contrarily to the above results, ozonation led to rapid decoloration. As a matter of fact, full destruction of color was observed in the first $15 \mathrm{~min}$ in all experiments, while more than $70 \%$ of color vanished in the first 5 min (Figures 4-6). It is obvious that, ozone attacked initially the chromophore part of the azo-reactive dyes (azo double bond), breaking it and leading to the formation of intermediate colorless products (e.g., nitrosamines) [4,5]. Moreover, the $\mathrm{pH}$ of the dye solutions dropped slightly, but clearly in all cases; from an initial value of 5-5.5 to a final $\mathrm{pH}$ of around 4.5-4.8, while temperature remained essentially constant throughout the experiment. The drop of $\mathrm{pH}$ is attributed to the dye decomposition and the formation of organic (carboxylic) and inorganic acids; a phenomenon that has been also described by other researchers during azo-dye decomposition by differentiated methods [21,24].

From the kinetics-modeling viewpoint, ozonation of dyeaqueous solutions is a gas-liquid reaction; ozone is the gaseous reactant while the dissolved azo-reactive dye is the reactant in the liquid (aqueous) phase. Either directly or indirectly, ozone reacts rapidly with the dye molecules [1,4]. Thus, assuming spontaneous chemical reaction, ozonation kinetics can be described as a mass-transfer-control process [28]. Moreover, dye concentration in water can be safely considered as not high ( $\max$ values: $3.07 \times 10^{-5}$ to $3.83 \times 10^{-5} \mathrm{M}$ ). At steady state conditions, the rate equation with respect to dye concentration $\left(C_{d}\right)$ can take the following simplified form of a pseudo-first order reaction [28]:

$$
-\mathrm{dC}_{\mathrm{d}} / \mathrm{dt}=\mathrm{kC}_{\mathrm{d}}
$$

From equation 1 , the following equation can be derived:

$$
\ln X=-k t
$$

where $X$ is the portion of the dye remaining into the aqueous solution $\left(X==C_{d} / C_{d o}\right), C_{d}=$ dye concentration at time $t$, and $C_{d o}=$ the initial dye concentration.

Based on the experimental data, Figure 7 presents the graphs of equation (2) for the ozonation of each azo-reactive dye solution. Indeed, the above assumptions, which led to the description of a pseudo-first order chemical reaction are verified accurately, as depicted from all the correlation coefficients $\left(\mathrm{R}^{2}\right)$ of Figure 7.

Although ozonation of azo-reactive dyes is indeed a very fast reaction, the combination of ozone with the RFAEF inductance device resulted to even faster decoloration. Compared to ozonation alone, a small but discrete and consistent increase of $\sim 5-10 \%$ in the destruction of color was observed in the first 5 min, in all cases (Figures 4-6). Moreover, the pH of the aqueous solutions dropped to around 4-4.2, indicating a higher degree of dye-molecule decomposition compared to ozonation alone. At the same time, temperature in the bubble column reactor increased $5-6{ }^{\circ} \mathrm{C}$ in all cases. The latter results are indicative of 
the synergetic effects of the combined process. Similarly to other hybrid processes $\left(U V / O_{3}, U S / O_{3}\right)[17,18]$, the above synergetic effects can be attributed to two (2) different causes. The first cause is the increase in the total mass-transfer coefficient of ozone through the gas-liquid interface. That is due to the cavitation effect of the alternating electric field action, which splits the air/ozone bubbles to myriads of smaller ones. Thus, the surface area of the gas-liquid interface increases, leading to the subsequent increase in total mass-transfer coefficient of ozone. The second cause is the rapid decomposition of ozone, forming free hydroxyl $(\mathrm{OH} \bullet)$ and other radicals due to the alternating electric field direct or indirect action (thermal decomposition due to temperature rising). As already stated above, the reaction speed of hydroxyl radicals with organic matter (azo-reactive dyes in our case) is thousands of times higher than that of ozone $[17,18]$.

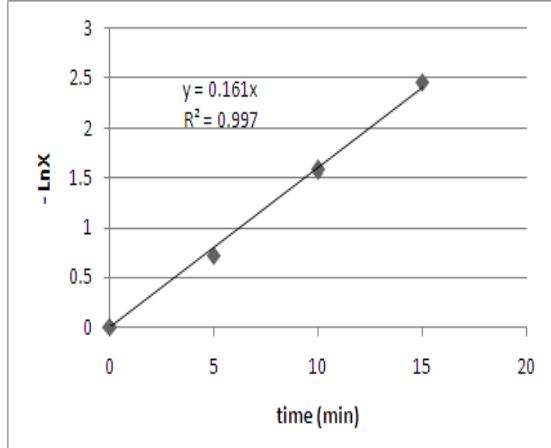

(a)

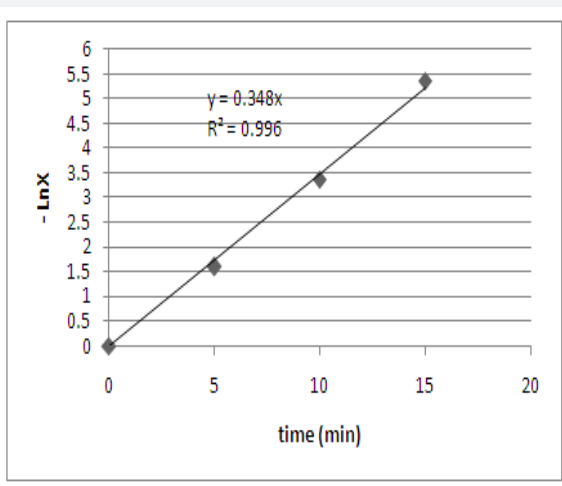

(b)

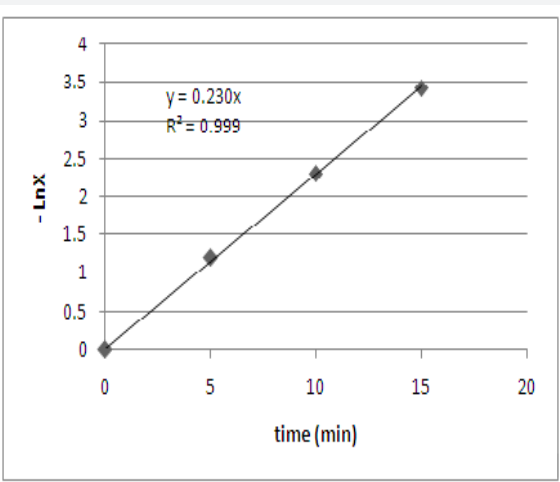

(c)

\section{(a) C.I. Reactive Yellow 84 \\ (b) C.I. Reactive Red 120 \\ (c) C.I. Reactive Blue 198}

Figure 7: Graphs of equation (2) for the ozonation of each azo-reactive dye.

Future work will focus on scaling up and the use of real textile wastewater for the experiments. Moreover, the development of an advanced and more effective RFAEF inductance device is also part of our main scientific targets.

\section{Conclusion}

Ozonation of azo-reactive dyes, used for dyeing cellulose fibers, in a bubble column reactor, led to rapid and effective decoloration of the respective aqueous solutions. Destruction of azo-reactive dyes was accompanied by a decrease in the $\mathrm{pH}$ of the aqueous solutions due to the formation of organic and/ or inorganic acids. Combining ozonation with a radio-frequency alternating electric field inductance device resulted in even faster decoloration of the azo-reactive dye aqueous solutions due to specific synergetic effects.

\section{References}

1. Gottschalk C, Libra JA, Saupe A (2009) Ozonation of Water and Waste Water: A Practical Guide to Understanding Ozone and its Applications, ( $2^{\text {nd }}$ Edn), WILEY-VCH.

2. Von Gunten U (2003) Ozonation of drinking water: Part I. Oxidation kinetics and product formation. Water Res 37(7): 1443-1467.

3. Von Gunten U (2003) Ozonation of drinking water: Part II. Disinfection and by-product formation in presence of bromide, iodide or chlorine. Water Res 37(7): 1469-1487.

4. Von Sonntag C, Von Gunten U (2012) Chemistry of Ozone in Water and Wastewater Treatment: From Basic Principles to Applications", IWA Publishing pp. 312.
5. Schiaffo CE, Dussault PH (2008) Ozonolysis in Solvent/Water Mixtures: Direct Conversion of Alkenes to Aldehydes and Ketones. J Org Chem 73(12): 4688-4690.

6. Johnson D, Marston G (2008) The gas-phase ozonolysis of unsaturated volatile organic compounds in the troposphere. Chem Soc Rev 37(4): 699-716.

7. Geletneky C, Berger S (1998) The Mechanism of Ozonolysis Revisited by ${ }^{17}$ O-NMR Spectroscopy. Eur J Org Chem 1998(8): 1625-1627.

8. Harrelkas F, Azizi A, Yaacoubi A, Benhammou A, Pons MN (2009) Treatment of textile dye effluents using coagulation-flocculation coupled with membrane processes or adsorption on powdered activated carbon. Desalination 235(1-3): 330-339.

9. Georgiou D, Aivasidis A (2012) Cotton-textile wastewater management: investigating different treatment methods. Water Environ Res 84(1): 54-64.

10. Sarayu K, Sandhya S (2012) Current Technologies for Biological Treatment of Textile Wastewater-A Review. Appl Biochem Biotechn 167(3): 645-661.

11. Gupta VK, Khamparia S, Tyagi I, Jaspal D, Malviya A (2015) Decolorization of mixture of dyes: A critical review. Glob J Environ Sci Manage 1(1): 71-94.

12. Roulia M, Vassiliadis AA (2009) Clay-catalyzed phenomena of cationicdye aggregation and hydroxo-chromium oligomerization. Micropor Mesopor Mater 122 (1-3): 13-19.

13. Roulia M, Vassiliadis AA (2008) Sorption characterization of a cationic dye retained by clays and perlite. Micropor Mesopor Mater 116(1-3): 732-740.

14. Georgiou D, Melidis P, Aivasidis A, Gimouhopoulos K (2002) Degradation of azo reactive dyes by UV radiation in the presence of hydrogen peroxide. Dyes Pigments 52(2): 69-78. 
15. Soares PA, Silva TF, Manenti DR, Souza SM, Boaventura RA, et al. (2014) Insights into real cotton-textile dyeing wastewater treatment using solar advanced oxidation processes. Environ Sci Pollut Res Int 21(2): 932-945.

16. Asghar A, Raman AAA, Daud WMAW (2015) Advanced oxidation processes for in-situ production of hydrogen peroxide/hydroxyl radical for textile wastewater treatment: a review. J Clean Prod 87: 826-838.

17. Cardoso JC, Bessegato GG, Zanoni MVB (2016) Efficiency comparison of ozonation, photolysis, photocatalysis and photoelectrocatalysis methods in real textile wastewater decolorization. Water Res 98: 3946.

18. Cui M, Jang M, Cho SH, Elena D, Khim J (2011) Enhancement in mineralization of a number of natural refractory organic compounds by the combined process of sonolysis and ozonolysis $\left(\mathrm{US} / \mathrm{O}_{3}\right)$. Ultrason. Sonochem 18(3): 773-780.

19. Sathishkumar P, Mangalaraja RV, Anandan S (2016) Review on the recent improvements in sonochemical and combined sonochemical oxidation processes - A powerful tool for destruction of environmental contaminants. Renew Sust Energ Rev 55: 426-454.

20. Babu SG, Ashokkumar M, Neppolian B (2016) The Role of Ultrasound on Advanced Oxidation Processes. Top Curr Chem (Cham): 374(5):75.
21. Sugiarto AT, Ito S, Ohshima T, Sato M, Skalny JD (2003) Oxidative decoloration of dyes by pulsed discharge plasma in water. J Electrostat 58: $135-145$.

22. Li Zhang, Sun B, Zhu X (2009) Organic dye removal from aqueous solution by pulsed discharge on the pinhole. J Electrostat 67: 62-66.

23. Bo Jiang, Zheng J, Qiu S, Wu M, Zhang Q et al. (2014) Review on electrical discharge plasma technology for wastewater remediation. Chem Eng J 236: 348-368.

24. Koutahzadeha N, Esfahania MR, Arcea PE (2016) Removal of Acid Black 1 from water by the pulsed corona discharge advanced oxidation method. J Water Process Eng 10: 1-8.

25. Jakobsen HA (2008) Chemical Reactor Modeling. Multiphase Reactive Flows, Ed. by Springer-Verlag Berlin Heidelberg.

26. Cardona SC, Lopez F, Abad A, Laboulais JN (2010) On Bubble Column Reactor Design for the Determination of Kinetic Rate Constants in GasLiquid Systems. Can J Chem Eng 88(4): 491-502.

27. Colour Index, The Society of Dyers and Colourists and American Association of Textile Chemists and Colorists.

28. Levenspiel $O$ (1998) Chemical Reaction Engineering, ( $3^{\text {rd }}$ Edn), WILEY.

\section{Your next submission with Juniper Publishers will reach you the below assets}

- Quality Editorial service

- Swift Peer Review

- Reprints availability

- E-prints Service

- Manuscript Podcast for convenient understanding

- Global attainment for your research

- Manuscript accessibility in different formats ( Pdf, E-pub, Full Text, Audio)

- Unceasing customer service

Track the below URL for one-step submission https://juniperpublishers.com/online-submission.php 